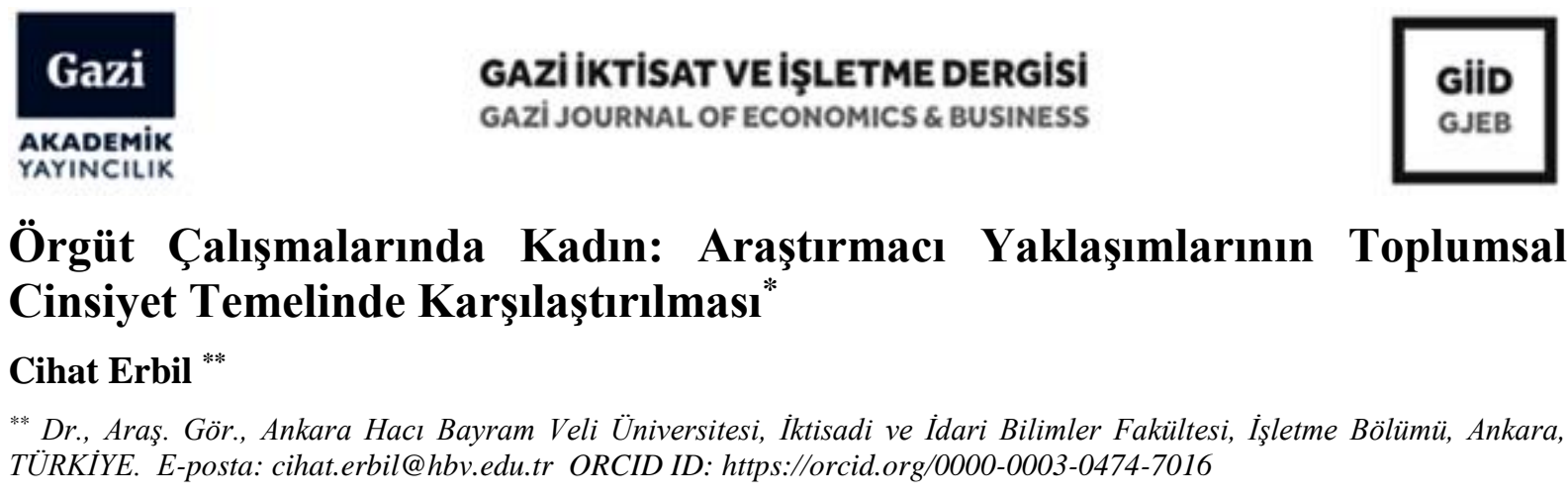

\section{MAKALE BÍLGİSi}

Geliș Tarihi: 24.09.2019

Kabul Tarihi: 15.01.2020

Çevrimiçi Kullanım

Tarihi: 12.02.2020

Makale Türü: Araştırma

makalesi

\section{Anahtar Kelimeler: \\ Kadın çalışmaları, toplumsal cinsiyet, örgüt çalışmaları, eleştirel gerçekçilik.}

\section{ÖZ}

Bu çalışmada, Türkiye'de Türkçe yayınlanmış örgüt çalışmalarında kadın odaklı çalışmaları, araştırmacıların toplumsal cinsiyet rollerine göre karşılaştırılmıştır. Çalışma kapsamında karşılaştırma yapabilmek için çalışmaları seçerken Tranfield vd. (2003) tarafından geliştirilen sistematik tarama prosedürü benimsenmiştir. Tarama sonucunda seksen dokuz yayını araştırmaya dahil edilmiştir. Örgüt çalışmalarında kadın odaklı olanlar, yönetim, kadın sorunları ve toplumsal cinsiyet başlıkları altında gruplanmıştır. Kadın çalışanların örgüt içerisinde karşılaştıkları sorunları değerlendiren çalışmaların ağırlıklı olarak kadın araştırmacılar tarafından yürütüldüğü tespit edilmiştir. Diğer gruplarda da kadın araştırmacıların sayısı yüksek olmakla birlikte, erkek araştırmacıların sayısı da görece fazladır. Ancak, genel olarak, araştırma kapsamındaki çalışmalarda, araştırmacıların konuya ve araştırmaya mesafeli kaldıkları değerlendirilmiştir.

\title{
Women in Organizational Studies: Comparison of Researcher Approaches on Gender Basis
}

\section{ARTICLE INFO \\ Received: 24.09 .2019 \\ Accepted: 15.01.2020 \\ Available online: 12.02 .2020 \\ Article Type: Research \\ article}

Keywords:

Women studies, gender, organization studies, critical realism

\begin{abstract}
In this study, I compared publications within the scope of organizational studies according to the gender roles of the researchers. In order to make comparisons, I adopted the systematic review procedure developed by Tranfield et al. (2003). In the organization studies, women-oriented ones could be grouped under the headings of management, women's problems and gender roles. I found that the studies evaluating the "problems" faced by women employees within the organization were mainly carried out by female researchers. In other groups, the number of female researchers was high, but the number of male researchers was relatively high. However, in general, in research studies, I found that researchers remain distant to the topic and research.
\end{abstract}

\section{Giris}

1970'lere kadar örgüt çalışmaları, örgüt içerisindeki bireyleri ve farklılıklarını, örgütsel yaşamı ihmal ederken, daha çok mesleki konulara odaklanıyordu (Schein, 1996). O döneme kadar "üretkenlik arayışında" olan, pozitivist yaklaşımlı çalışmaların hakim olduğu, neden-sonuç ilişkisinin "bilimsel

\footnotetext{
* Doi: https://doi.org/10.30855/gjeb.2020.6.1.004
} 
yöntemlerle" kesin olarak ortaya konabileceği ve açıklanabileceği inancı ile yürütülen çalışmalar, pozitif bilimlerdeki görelilik ile paralel olarak evrildi.

Örgüt çalışmalarında kadın konusu da bu evrimsel süreçten kendi payına düşeni almıştır. Bir süre kadınlar (ve erkekler) cinsiyetleri ve cinsiyet rollerinden muaf bir şekilde işyerinde var oldukları varsayılmış, işyerinin kapısına girdiklerinde, eril normların içselleştirilip normalleştirildiği çalışma ortamına uyumları çerçevesinde değerlendirilmiştir (Gutek ve Cohen, 1987; Acker, 1990, 1998). Yönetsel rollere maskülenlik atfedilirken (Heilman, 1983, 1995; Acker, 1990; Fletcher, 2004) kadınların bu rollerden uzak olduğu, bunlarla uyumsuzluk içerisinde oldukları ya da üretkenlik-karşıtı davranışlar sergiledikleri şeklinde yorumlanmıştır (Sinclair, 1998, 2000). Kadınların üretime ve ekonomiye katılımlarına ilişkin ve "ikincil güç" olarak kabul edildiği, çoğu erkek teorisyenler tarafından yürütülmüş; meşruiyet kazanmak için "bilimsel", "pozitivist" ve "objektif" araştırma söylemleri kullanan (!) araştırmaların gerçekleştirildiği izlenmiştir (Aliefendioğlu ve Özbilgin, 2001).

Kadın hareketlerinin gelişimi (Wilson, 1996; Calás ve Smircich, 1999; Gherardi, 2003; Lewis, 2014) ve yönetim çalışmalarında işaret edilen yaklaşımsal dönüşüm, örgüt çalışmalarında kadın çalışmalarının toplumsal cinsiyet rolleri anlayışı ile kök salmasını olanaklı kılmıştır. Pratikte, işletmelerin ve devletlerin de ilgisinin artması alana projektörlerin yönlendirmesini teşvik etmiştir (Grosser ve Moon, 2019). Toplumsal cinsiyet rolleri, örgüt çalışmalarında da yapısal, kültürel ve söylemsel olarak irdelenmeye başlanmıştır (örneğin Acker, 1990, 2006, 2011; Meyerson ve Kolb, 2000) Örgütlerde kadın çalışmaları, "kadın olmayı" biyolojik temelli bir ayrımın ötesinde yorumlamış; "kadın olmak" sosyokültürel ve tarihsel durumların bir sonucu olarak değerlendirilmitşir (Alvesson ve Billing, 2009, s. 21) —örgüt çalışmalarında da "kadınlık (Holmes ve Schnurr, 2006; Fernando ve Cohen, 2014; Nicolson, 2015)" ve "kadın olma (Harris, 1995; Shaw, 2010)", "kadın çalışan olma" böylece ele alınmaktadır.

Nitekim, toplumsal cinsiyet rolleri temelinde kadın çalışmaları, bugün, esasen, kurumların, süreçlerin ve genel anlamda sosyal ilişkilerin anlaşılması; eşitsizlik, baskı, muhalefet, itaat ilişkilerini karakterize olan sorunların ortaya konulması için yürütülmektedir. Bunların yanında, cinsiyet ilişkileri sosyal yapılar olarak da görülür (Alvesson ve Billing, 2009, s. 21). Buna dayalı olarak, kadın çalışmalarının doğası eleştirel gerçekçiliği (critical realism) talep eder (Francis, 2002; Nogueira, 2007; Gunnarsson vd., 2016; Fletcher, 2017).

Eleştirel gerçekçilik açısından, gerçeği üreten yapının açıklığa kavuşturulması için insanların eylemlerinin anlaşılması yeterli değildir. Çünkü yapı çok katmanlı, tarihsel ve bağlamsaldır. Eylem yapının bir sonucu olabilir, ama, her yapı kendisini anlamlandırabilecek eylemler üretmek durumunda değildir (Özbilgin ve Erbil, 2019). Bu durum da pozitivizmin araştırmaciya yüklediği araştırma içerisindeki "nesnel gözlemci (Sayer, 2004; Fleetwood, 2005; Al-Amoudi ve Willmott, 2011)" ve "bilgi üreticisi (Smirthwaite ve Swahnberg, 2016)" rolünü tartışamaya açar. Araştırmacı, kendi tarihsel deneyimleri, sosyal rolleri ve bilinci ile araştırmanın içerisindedir. Araştırmayı ve araştırma teknik ve araçlarını da kendi birikimi ile kurgular. Buradan gelen öznellikten muaf bir araştırma yürütmek, en azından sosyal bilimlerde, mümkün değildir (Noor, 2008)-bunda bir sorun yoktur da. Bu bakımdan araştırmacıdan beklenen, kendi birikimlerinin araştırma üzerindeki ve sürecindeki etkisini ve hatta araştırma içerisindeki etkileşimi (araştırmac1 - araştırma etkileşimi) ortaya koyabilmesi, görünür k1lması ve yoruma sunmasidır (Hardy vd., 2001; Cunliffe, 2003; Johnson ve Duberley, 2003; Alvesson vd., 2008).

$\mathrm{Bu}$ çalışma da, kadın çalışmalarında araştırmacılardan beklenen rollerin araştırmacılarca sergilenen rollerle kıyaslamak için tasarlanmıştır. Çalışmada, örgüt çalışmalar kapsamına giren kadın çalışmalarının esasına ne derece yaklaşılabildiğinin tartışılması hedeflenmiştir. Araştırmacıların cinsiyet rollerinin etkisinin izlerini çalışmalar üzerinden sürmek de bu çalışmanın bir diğer amacıdır. Araştırma eğilimlerinin gecikmeli takibinde olan Türkiye'de yayımlanmış çalışmalar üzerinde bu amaçlarla bir araştırmanın tasarlanıp yürütülmesinin, sosyokültürel çıkarımlara da olanak sağlayacağ 1 düşünülmüştür ve araştırmada Türkiye'de yayımlanmış çalışmaları incelenmiştir. 


\section{Yöntem}

Örgüt çalışmalarında toplumsal cinsiyet temelli kadın konusu -kadınların kendilerine atfedilen toplumsal cinsiyet rollerinden dolayı karşılaştıkları sorunlar, kadınların yönetim ve iş gücü içerisindeki yeri, kadın emeği ve emeğinin bedeli gibi- dünyada 1970'li yıllarından başında ivme kazanmıştır. Türk literatüründe ise bu ivmenin henüz olduğu gözlemlenmektedir. Bu bakımdan, çalışmanın Türk literatüründeki şekillenmesini ve yönünü anlamlandırabilmek için de, Türk dergilerinde yayımlanan makaleler üzerinden bu çalışmanın kurgulanması anlamlı bulunmuştur. Bunun için. Tranfield vd. (2003) tarafından ortaya konulan sistematik tarama protokolünü kullanılarak "kadın" merkezli örgüt çalışmaları listelenmiştir (Tablo 1). Listelenen bu makaleler, yıllarına ve yazarların cinsiyetine göre tasniflenmiştir (Tablo 4). Betimsel bir yaklaşımla analiz edilmiştir.

Tranfield vd. (2003), tarafından önerilen tarama protokolü, yönetim araştırmalarında sıklıkla kullanılır. Önerilen bu protokolde temel hedef, tarama konusu ile ilgili yayınların gözden kaçırılmasını önlemek, araştırma için anlamlı olanlarını bir araya getirmek ve ilgisiz çalışmaların ayıklanmasını kolaylaştırarak yerinde bulgulara erişilmesini kolaylaştırmaktır.

Söz konusu protokol üç temel adımdan oluşur (Tranfield vd., 2003): (1) Taramanın planlanması, (2) taramanın gerçekleştirilmesi ve (3) elde edilen bulguların raporlanması ve yaygınlaştırılması.

Bu çalışmada da söz konusu üç aşama takip edilerek sistematik tarama gerçekleştirilmiştir. Maier vd. (2016)'nin çalışmalarında şablonlaştırdığı süreç referans alınmıştır (Tablo 1).

Öncelikle, Tranfield vd. (2003) ve Maier vd. (2016) tarafından da belirtildiği üzere tarama kapsamının belirlenmesi için beş örnek çalışmadan oluşan kısa bir liste oluşturulmuştur. Bu listenin oluşturulmasında ve sistematik taramanın devam eden süreçlerinde alanla ilgili deneyimi olan bir ekibin yönlendirmesine ihtiyaç duyulmuştur. Örgüt ve/ya da toplumsal cinsiyet çalışmaları alanında çalışmalarını gerçekleştirmekte olan beş kişiden oluşan bir akademisyen grubunun görüşleri alınmıştır. Örnek çalışma listesinin oluşturulmasında, üç temel referans bulunmaktadır: (1) Çalışmaların örgüt ve kadın çalışmalarının kesişiminde olması, (2) çalışmaların amprik olması ve (3) Türk dergilerinde yayımlanmış olması. Bu kriterlere göre her bir akademisyen beş çalışma önermiştir. Önerilen çalışmaları derlenmiştir (aynı çalışmalar ihmal edildiğinde on üç çalışma oluyordu) ve akademisyenlerden oluşan bu listeyi, örnek listede olması gerektiği düşündüklerini, önem derecesine göre, 5'ten 1'e kadar puanlamasını istenmiştir. Toplam puanlara göre ilk beşte yer alan çalışmalar örnek listeyi oluşturmuştur (Tablo 2).

Listede yer alan çalışmalara göre tarama için kullanılacak ilk tarama terimleri belirlenmiş ve ekipte yer alan akademisyenlerin görüşüne sunulmuştur; geri bildirimlere göre tarama terimleri kesinleşmiştir (Tablo 3). Bu terimlere göre, tarama süreci başlatılmıştır (ikinci aşama). Tarama için TÜBİTAK Ulakbim tarafından taranan, TR Dizin veri tabınında, Akademia Sosyal Bilimler Endeksi (Asos Index)'nde yer alan dergilerde ve Google Scholar üzerinden tarama yapılmıştır. Taramayı, tarama listesindeki terimlerle ve "kadın", "erkek" ifadelerini de içerekce şekilde, makalelerin başlıklarında, anahtar kelimelerinde ve özetlerinde gerçekleştirilmiştir. 451 farklı çalışma listelenmiştir. Bu çalışmalarda ilgililik durumuna göre ayıklama yapılmıştır. Ayıklama yapılırken dört ölçütten yararlanılmıştır: Çalışmanın (1) sosyal bilimler kapsamında yer alması, (2) ampirik olması, (3) tam metnine erişilebiliyor olması ve (4) tam metnin Türkçe olması.

$\mathrm{Bu}$ ölçütlere göre yapılan ayıklamadan sonra 56 çalışma ortaya çıkmıştır. Bu çalışmaların kaynakçaları ve bu çalışmalara atıf veren çalışmaları gözden geçirilmiştir (kartopu yöntemi). Bunlara dokuz çalışma daha eklenmiştir. Toplam 65 çalışma tasnif edilmiş ve arama ölçütleri çerçevesinde kodlanmıştır. Kodlama yapılırken, bu çalışmaları tanımlayabilecek yeni tarama terimleri ortaya konulmuş, bu terimler görüş bildiren beş akademisyenle paylaşılmıştır. Onlardan alınan geri dönüşlere göre, böylece, iki arama döngüsü için yeni terimler belirlemiştir (Tablo 3). İkinci döngü, yeni terimler kullanılarak, birinci döngüdeki adımlarla işletilmiştir. Bu döngünün sonunda da 24 yeni yayını listeye eklemiştir.

Toplam iki döngü ile tarama süreci tamamlanmıştır. Yerli veri tabanlarında taranan, Türkçe, ampirik örgüt çalışmalarında kadın odaklı 89 çalışmayı listelemiştir. Her bir çalışma, arama terimleri 
çerçevesinde kodlanmış olmuştur. Çalışmaları, yazarların cinsiyeti ve yayın yıllarına göre, kodlamaları da gösterilerek Tablo 1'de listelenmiştir (üçüncü aşama).

Tablo 1

Sistematik Tarama Süreci

\begin{tabular}{|c|c|c|c|c|}
\hline Aşama & Adım & Amaç & Teknik & Sonuç \\
\hline $\begin{array}{l}\text { 1. Planlama: } \\
\text { Kapsamın } \\
\text { belirlenmesi }\end{array}$ & $\begin{array}{l}\text { İlk kapsamı } \\
\text { tanımlama }\end{array}$ & $\begin{array}{l}\text { İlk tarama } \\
\text { terimlerini } \\
\text { belirleme }\end{array}$ & $\begin{array}{l}\text { Seçilen beş makalenin } \\
\text { yakından okunması }\end{array}$ & $\begin{array}{l}\text { İlk tarama } \\
\text { terimlerinin } \\
\text { belirlenmesi }\end{array}$ \\
\hline \multirow[t]{4}{*}{$\begin{array}{l}\text { 2. Taramanın } \\
\text { gerçekleştirilmesi } \\
\text { Ilk döngü }\end{array}$} & $\begin{array}{l}\text { İlgili potansiyel } \\
\text { literatürün } \\
\text { tanımlanması }\end{array}$ & $\begin{array}{l}\text { İlgili literatür } \\
\text { havuzunu } \\
\text { oluşturma }\end{array}$ & $\begin{array}{l}\text { Veri tabanlarından ilk } \\
\text { tarama terimlerinin } \\
\text { kullanarak tarama } \\
\text { yapılması }\end{array}$ & $\begin{array}{l}451 \text { potansiyel } \\
\text { olarak ilgili yayın }\end{array}$ \\
\hline & $\begin{array}{l}\text { İlgili literatürün } \\
\text { seçilmesi }\end{array}$ & $\begin{array}{l}\text { İlgili literatürü } \\
\text { tanımlama }\end{array}$ & $\begin{array}{l}\text { İlgili literatüre } \\
\text { erişebilmek için seçim } \\
\text { ölçütlerinin } \\
\text { iyileştirilmesi: Bu } \\
\text { kriterler üzerinden } \\
\text { havuzda tarama } \\
\text { yapılması }\end{array}$ & 56 ilgili yayın \\
\hline & $\begin{array}{l}\text { Geriye ve ileriye } \\
\text { doğru kartopu }\end{array}$ & $\begin{array}{l}\text { İlgili literatürü } \\
\text { tanımlama }\end{array}$ & $\begin{array}{l}\text { Seçilen literatürün } \\
\text { kaynakçaları ve bu } \\
\text { literatüre yapılan } \\
\text { atıflar üzerinden } \\
\text { tarama yapılması }\end{array}$ & $\begin{array}{l}\text { İlgili yayınlara ek } \\
9 \text { yayın }\end{array}$ \\
\hline & $\begin{array}{l}\text { Verinin çıkarılması } \\
\text { ve analiz edilmesi }\end{array}$ & $\begin{array}{l}\text { İlgili } \\
\text { literatürden } \\
\text { bilgi sağlama }\end{array}$ & $\begin{array}{l}\text { Literatürün tarama } \\
\text { kriterleri üzerinden } \\
\text { kodlanarak } \\
\text { dosyalanması }\end{array}$ & $\begin{array}{l}\text { Her bir yayı̈ın } \\
\text { sorunsal, yöntem, } \\
\text { sonuç ve } \\
\text { yazarlarına göre } \\
\text { analiz edilmesi }\end{array}$ \\
\hline \multirow[t]{4}{*}{ İkinci döngü } & $\begin{array}{l}\text { İleri düzeyde } \\
\text { potansiyel } \\
\text { literatürün } \\
\text { tanımlanması }\end{array}$ & $\begin{array}{l}\text { İlgili literatür } \\
\text { havuzunu } \\
\text { genişletme }\end{array}$ & $\begin{array}{l}\text { Veri tabanlarından } \\
\text { yeni tarama terimlerini } \\
\text { kullanarak tarama } \\
\text { yapılması }\end{array}$ & $\begin{array}{l}122 \text { potansiyel } \\
\text { olarak ilgili yayın }\end{array}$ \\
\hline & $\begin{array}{l}\text { İlgili literatürün } \\
\text { seçilmesi }\end{array}$ & $\begin{array}{l}\text { İlgili literatürü } \\
\text { tanımlama }\end{array}$ & $\begin{array}{l}\text { Seçim ölçütleri } \\
\text { kullanılması }\end{array}$ & 13 ilgili yayın \\
\hline & $\begin{array}{l}\text { Geriye ve ileriye } \\
\text { doğru kartopu }\end{array}$ & $\begin{array}{l}\text { İlgili literatürü } \\
\text { tanımlama }\end{array}$ & $\begin{array}{l}\text { Seçilen literatürün } \\
\text { kaynakçaları ve bu } \\
\text { literatüre yapılan } \\
\text { atıflar üzerinden } \\
\text { tarama yapılması }\end{array}$ & $\begin{array}{l}\text { İlgili yayınlara ek } \\
11 \text { yayın }\end{array}$ \\
\hline & $\begin{array}{l}\text { Verinin çıkarılması } \\
\text { ve analiz edilmesi }\end{array}$ & $\begin{array}{l}\text { İlgili } \\
\text { literatürden } \\
\text { bilgi sağlama }\end{array}$ & $\begin{array}{l}\text { Literatürün tarama } \\
\text { kriterleri üzerinden } \\
\text { kodlanarak } \\
\text { dosyalanması }\end{array}$ & $\begin{array}{l}\text { Her bir yayının } \\
\text { sorunsal, yöntem, } \\
\text { sonuç ve } \\
\text { yazarlarına göre } \\
\text { analiz edilmesi }\end{array}$ \\
\hline $\begin{array}{l}\text { 3. Bulguların } \\
\text { raporlanması }\end{array}$ & & & & \\
\hline
\end{tabular}


Tablo 2

Tarama Kapsamının Belirlenmesinde Referans Alınan Çalışmalar

Çitçi, O. (1979). Türk Kamu Yönetiminde Kadın Görevliler. N. Abadan-Unat,(Der.), Türk Toplumunda Kadın, Ankara: Türk Sosyal Bilimler Derneği, 241-270.

Lordoğlu, K. (1987). Yüksek Öğretim Gören Kadın İşgücü Adayları ve Çalışma Eğilimleri. ODTÜ Gelişme Dergisi, Cilt: 14.

Kutal, G. Sosyal Politika Açısından Çalışan Kadının Sorunları. Kiplas Dergisi, Sayı 12.

Koray, M. (1993). Çalışma Yaşamında Kadın Gerçekleri (Vol. 23). Banka, Sigorta İşçileri Sendikası.

Ayaz, N. (1993). Türkiye'de Çalışan Kadınların Sorunlarına Yönelik Bir Inceleme: Tekstil Işkolundan Örneklerç. Dokuz Eylül Üniversitesi İktisadi ve İdari Bilimler Fakültesi Dergisi, C8/S1, 175-191.

Tablo 3

Arama Terimleri

\begin{tabular}{ll}
\hline Birinci Döngü Tarama & İkinci Döngü Tarama \\
\hline yönetim & örgüt, organizasyon \\
& işletme, firma, kurum \\
& katılım \\
& temsil, temsiliyet \\
& girişim, girişimci, girişimcilik \\
& ayrımcıllk \\
sorun & şiddet \\
& eşitsizlik, eşitlik \\
farklılık & kariyer \\
& \\
toplumsal cinsiyet & cinsiyet rolleri \\
& aile \\
\hline
\end{tabular}

Örgüt çalışmalarında kadın eksenli araştırmaları, "kadın çalışmalarının esasına" olan mesafesini yorumlayabilmek için betimsel analiz gerçekleştirilmiştir. Betimsel analiz, kodlanan verinin temalar çerçevesinde yorumlanmasını olanaklı kılan bir yaklaşımdır (Yıldırım ve Şimşek, 2011, s. 224). Arama terimleri ile kodlanan çalışmalar, birinci kodlama döngüsündeki tarama terimleri tema olarak kabul edilerek yorumlanmıştır. Ayrıca, araştırmacıların toplumsal cinsiyet rollerinin çalışmaları üzerindeki izlerini sürebilmek için, araştırma cinsiyetleri üzerinden de yorumlamaya gidilmiştir. 
Tablo 4

Tarama Sürecinin Bulguları

\begin{tabular}{|c|c|c|c|c|c|c|c|c|c|c|c|c|c|c|}
\hline \multirow[b]{3}{*}{$\begin{array}{l}\text { Yazar } \\
\text { Cinsiyeti }\end{array}$} & \multicolumn{14}{|c|}{ Yazarlar } \\
\hline & \multicolumn{2}{|c|}{ Tek Yazarlı } & \multicolumn{3}{|c|}{ İki Yazarlı } & \multicolumn{4}{|c|}{ Üç Yazarlı } & \multicolumn{5}{|c|}{ Dört ve Daha Fazla Yazarlı } \\
\hline & Kadın & Erkek & $\begin{array}{c}\text { Biri } \\
\text { Kadın }\end{array}$ & $\begin{array}{l}\text { Tamamı } \\
\text { Kadın }\end{array}$ & $\begin{array}{c}\text { Tamamı } \\
\text { Erkek }\end{array}$ & $\begin{array}{c}\text { Biri } \\
\text { Kadın }\end{array}$ & $\begin{array}{c}\text { İkisi } \\
\text { Kadın }\end{array}$ & $\begin{array}{c}\text { Tamamı } \\
\text { Kadın }\end{array}$ & $\begin{array}{c}\text { Tamamı } \\
\text { Erkek }\end{array}$ & $\begin{array}{c}\text { Biri } \\
\text { Kadın }\end{array}$ & $\begin{array}{l}\text { İkisi } \\
\text { Kadın }\end{array}$ & $\begin{array}{c}\text { Üçü } \\
\text { Kadın }\end{array}$ & $\begin{array}{c}\text { Tamamı } \\
\text { Kadın }\end{array}$ & $\begin{array}{c}\text { Tamamı } \\
\text { Erkek }\end{array}$ \\
\hline Yillar & & & & & & & & & & & & & & \\
\hline $\begin{array}{l}2019- \\
2010\end{array}$ & 15 & 9 & 15 & 8 & & 3 & 3 & & 1 & & & 4 & 4 & \\
\hline $\begin{array}{l}2009- \\
2000\end{array}$ & 2 & 2 & & 3 & & & & & & & 1 & & & \\
\hline $\begin{array}{l}1999 \text { - } \\
1990\end{array}$ & 3 & & 1 & 2 & & & 1 & & & & & & & \\
\hline $\begin{array}{l}1989- \\
1980\end{array}$ & 4 & & 2 & & & & 1 & & & & & & & \\
\hline $\begin{array}{l}1979- \\
1969\end{array}$ & 2 & 1 & & & & & & & & & & & & \\
\hline
\end{tabular}

\section{Bulgular}

\subsection{Yönetim}

Tarama kapsamında kadın merkezli örgüt çalışmalarından ilki "yönetim” anlayışı çerçevesinde gruplandırıldı. Bu çalışmalar, yönetsel sistemin tanımlanması; yönetimde temsil, katılım ve güç; bireysel ve örgütler kariyer yönetimi; girişim, girişimci ve girişimcilik bağlıklarında toplanıyordu.

Bu başlıkta toplanan çalışmaların, diğer başlıkta gruplanan çalışmalara kıyasla, büyük kısmının ortak yazarlı olduğu, bu çalışmaların üretiminde kadın araştırmacıların erkekler ile işbirliği içerisinde olduğu gözlemlenebiliyordu. Yalnızca erkekler tarafından yürütülen çalışmaların da bu başlıkta daha fazla olduğu da söylenebilir.

Çalışmaların büyük kısmı nicel yöntemlerle kurgulanmıştı. Temel yönelimleri de kadınların örgüt içerisindeki yerini, erkeklerin konumları ile kıyaslayarak açıklamak olduğu görülüyordu. Girişimci ve girişimcilik konusunda, yerleşik bir literatürün oluştuğu "kadın girişimciliği"nde toplandığı, kadın girişimcilerin "özellikleri”, kadınların girişimcilik niyetlerinin ve eylemlerinin hangi engellerle karşılaştığı değerlendiriliyordu. Kadın girişimciliği çerçevesinde engelleri ele alan çalışmaların yoğunlukla kadın araştırmacılar tarafindan gerçekleştirilmiş olması da bir diğer bulgu oldu.

Kadınların yönetsel kademelerdeki yeri ve kadın çalışanların performansları (üretken davranışları) da bu gruptaki çalışmaların arasında yer alıyordu. İşletmelerin finansal performansı ile kadın yöneticiler ya da yönetim kurulu üyelerinin varlığı arasında bağ kuran çalışmalar gözlemlendi. $\mathrm{Bu}$ çalışmaların neredeyse tamamında, finansal performansın artırılmasında kadınların varlığının "araçsallığı" vurgulanırken, hakim literatürde "farklılıkların yönetimi”" çerçevesinde ele alının eleştirel nitelikli bakış açısından uzak bir dilin kullanıldığı ifade edilebilir. Bu çalışmaların hiçbirinde "Nasıl?" sorusuna yanıt aranmamış olduğu (nitel bir sorgulama gerekirdi), finansal veri üzerinden teknik analizlerin yürütüldüğü görülmektedir.

\subsection{Sorun}

Örgüt içerisinde ve mesleki çalışma alanında kadınların karşılaştıkları sorunları ele alan örgütsel çalışmalar ise ikinci grubu oluşturdu. Kadın olmanın getirdiği zorlukların değerlendirilmesinin kadın 
çalışmalarının esası olduğu düşüncesi ile bu grubun oluşturulmasının uygun olduğu düşünüldü. Tarama terimlerinin belirlenmesinde yer alan ve tarama sürecinde destek olan ekip de bu görüşü desteklemişti.

Örgüt çalışmalarında kadın sorunlarının ilk taramada, kadınların toplumsal cinsiyet rollerinden kaynaklandığına işaret eden (ancak bu rolleri açıkça da değerlendirmeyen) çalışmaları görmek tabii ki şaşırtıcı olmadı. Kadınların karşılaştıkları ayrımcılık ve kadınların örgüt içerisindeki maruz kaldıkları (mobbing, taciz gibi) çeşitli şiddetler de bu çalışmaların konusuydu.

Kadın çalışanlarının kariyer yönetimi ile ilgili çalışmalara bu başlık altında vermeye karar verildi. Çünkü bu çalışmaların büyük kısmı "cam tavan" ile ilişkilendiriliyordu.

Tarama süreci sonucunda araştırma kapsamına alınan çalışmalar yıllar itibarıyla değerlendirildiğinde, kapsamda yer alan çalışmaların ilk örneklerinin kadın sorunlarına ilişkin olduğu ve bunların ağırlıkla kadın araştırmacılar tarafından sunulduğu görülmektedir. Ampirik çalışma içermemesi nedeniyle kapsam dışında tutulan çalışmaların da, yıllar itibarıyla, ağırlıkla bu kesişimde yer aldığı söylenebilir.

Kadın emeğinin değerlenmesi, kadınların maruz kaldığı ayrımcılıklara ilişkin çalışmaların büyük oranda kadın araştırmacılar ya da kadın ağırlıklı bir ekip tarafından yürütülmüş olması bu başlıkta çalışmalara ilişkin bir bulgudur. Ancak, kadınların karşılaştığı şiddeti ele alan çalışmalarda, diğer alt başlıklarda kodlanan çalışmalara göre, daha fazla erkek araştırmacının yer aldığını da belirtmek gerekir. Bu çalışmalarda nicel yöntemlerin kullanılmış olması, sorunun kaynağını tespit etmekten ya da sorunlara çözüm önerisi getirmekten ziyade, tespit yapmakla yetinilmiş olması, bu çalışmalara ilişkin başka bir gözlemdir.

\subsection{Toplumsal cinsiyet}

Sorun başlığında gruplanan çalışmalarda, kadınların cinsiyet rollerinden kaynaklanan sorunlara işaret edildiği ifade edilmişti. Ancak bu çalışmalarda cinsiyet rolleri çalışmaların temel araştırma konusu değildir. Araştırmaların merkezine toplumsal cinsiyet rollerini yerleştiren örgüt çalışmaları bulunuyordu. Bunları, kıyaslamalı olarak değerlendirebilmek için ayrı bir grupta ele almanın uygun olacağı düşünüldü.

$\mathrm{Bu}$ gruptaki çalışmalar, diğer gruptaki çalışmaları çapraz kesiyordu, ancak onlardan cinsiyet rollerini doğrudan ele alması, cinsiyet rollerini yapı ve sosyal iletişim rolü yüklemesi ile ayrıldılar.

Bu çalışmaları yürütenlerin yoğunlukla kadın olduğu, bu gruptaki çalışmalara ilişkin bir bulgudur. Çalışmalarda, nicel araştırma yöntemleri kullanılmıştır. Kadınların, kendilerine yüklenen kadınlık rollerinin yönetsel beceriler ile ilişkisi, örgüt içerisindeki konumlarında rollerinin etkisi pozitivist bir yaklaşımla değerlendirdiği görülebilmektedir.

\section{Tartışma ve Sonuç}

$\mathrm{Bu}$ çalışmada, örgüt çalışmalarında kadın odaklı araştırmaları, çalışma konularının sorunsallaştırılma ve yönetilme biçimin, araştırmacıların toplumsal cinsiyet rolleri üzerinden değerlendirilmiştir. Kadın hareketlerinin etkisi ve örgüt çalışmalarında eleştirel gerçekçi yaklaşımların kadın çalışmalarındaki merkezi konumu ve işlevine dayanarak, araştırmacıların rolünün değerlendirilmesinin anlamlı olacağı düşünülmüştür.

Örgüt çalışmalarında kadın konusunu ele alan araştırmacıların daha fazla kadın araştırmacılar olduğu görülmektedir. Bu çalışmaların önemli bir kısmı, kadın çalışanların örgüt içerisindeki sorunlarına odaklanıyordu. Söz konusu çalışmalar, diğer çalışmalardan, daha fazla nitel yöntemin benimsenmesi ile ayrilyyordu.

Yönetim ve toplumsal cinsiyet başlığında gruplanan çalışmalarda ise erkek araştırmacıların yoğunluğu görece fazlaydı (ama yine de kadın araştırmacıların toplam sayısının üzerinde değildi). Bu kapsamdaki çalışmalarda ise nicel yöntemlerin benimsemesi de diğer bir dikkat çeken noktaydı.

Araştırma kapsamında değerlendirilen çalışmaların çok büyük bir kısmında, araştırmacıların konuya anlatımsal bir mesafe koyduğunu, edilgen bir benimsediği izlenmektedir. Kadın çalışmalarında 
araştırmacıya yüklenen özgürleştirme ve demokratikleştirme misyonuna henüz yaklaşılmadığı açıktı. Kadın araştırmacıların, kendi toplumsal ve mesleki yapı içerisindeki deneyimlerine dayanmıyor olmas1 da diğer bir gözlemdir. Bunun birkaç nedeni olduğu düşünülmektedir: Maskülenlikle ilişkikendirilmiş yönetsel rollerin ve örgütsel yapının henüz araştırmacılarca sorgulanmamış olması, bu nedenlerden birisidir. Bu nedenle, örgüt içerisindeki kadının, "objektif ölçütlerle" mesafesinin değerlendirildiği çalışmalar sunulmuştur. Araştırmacıların meşruiyet ve kabul görme kaygısı da bu durumun nedenlerinden birisi olarak değerlendirilebilir. Kadın araştırmacıların kadın sorunları ile yüzleştiği, araştırmacının kendi varlığını ortaya koymasını olanaklı kılan nitel araştırma yöntemlerinin kullanıldığ çalışmalarda dahi araştırmacıların çalışmaya kullanılan dil ile mesafe koyduğu, "dayanakların" araştırmaların objektifleştirilmesi kaygısı ile sunulduğu görülümektedir. Bunların yanına, tüm akademik çalışmalarda güdülen kaygıları da etkisinin olabileceğini de belirtmek gerekir: Rekabetçiliğin getirdiği sığlık (Ozbilgin 2009; Dameron ve Durand, 2017), performans kaygıları, teşvik politikaları ve üretim niceliğine dayalı rekabet (Willmott, 2011) de anlam arayışında olması gereken alanları dahi bu şekilde kuraklaştırabilmektedir.

Oysa, kadın çalışmaları ve eleştirel gerçekçilik kesişiminde anlam bulabilecek örgüt çalışmaları, araştırmacılara araştırma repartuvarlını genişletme, veri kanallarını açma ve çeşitlendirme, araştırmacı olarak kendilerini de araştırmaya dahil etme olanağı sağlar (Özbilgin ve Erbil, 2019). Performatif (performative) (Gergen ve Jones, 2008), düşünümselci (reflexive) (Johsnon ve Duberley, 2003) ve özgüleşimci (emancipative) (Oliver, 1997) araştırma yöntemleri bu nefesi verebilecektir.

Tabii bu değerlendirmeler, Türkiye'de, Türkçe olarak yayımlanmış çalışmalara yöneliktir. Türkiye'deki yönetsel yazının Kuzey Amerika'nın üretim modeli olan pozitivizmin esaretinde, nicel araştırma yöntemleri fetişizminde olduğu gerçeği ile de okumak gerekir (Özen, 2000, 2002). Bunun yanı sıra, kadın hareketlerinin marjinelleştirilmiş olmasının da bu sığlıkta etkisinin olduğunu söylemem yanlış olmayacaktır.

Taramanın, Türkiye'deki yayınlarda Türkçe olarak yayımlanmış çalışmalarda gerçekleştirilmiş olması, bu çalışmaya bir kısıt oluşturduğunu bu noktada belirtmek yerine olur. Tarama alanını daraltmak ve "yerel" yayınlardaki durumu resmedebilmek için bu yol tercih edilmiştir. Tarama diline özellikle İngilizcenin eklenmesi bulguları farklılaştırabilir.

Sistematik tarama sürecine destek olan ekip beş akademisyenden oluşuyordu. Tranfield vd. (2003) sistematik tarama için geniş bir ekip öneriyor. $\mathrm{Bu}$ da çalışmanın bir diğer kısıdı olarak değerlendirilmelidir.

\section{Kaynakça}

Acker, J. (1990). Hierarchies, jobs, bodies: a theory of gendered organization. Gender and Society, 4 (4), 139158.

Acker, J. (2006). 'Gender and organizations', pp. 177-195. İçinde, Salzman Chafetz, J. (ed). Handbook of the Sociology of Gender. New York: Springer.

Acker, J. (2011). 'Theorizing gender, race and class in organizations', pp. 65-81. İçinde, Jeanes, E. L., Knights, D. and Martin, P. Y. (eds) Handbook of Gender, Work and Organization. Chichester: Wiley.

Acker, J. (1990). Hierarchies, bodies, and jobs: a theory of gendered organizations. Gender \& Society, 4(1), 13958.

Acker, J. (1998). The future of 'gender and organizations': connections and boundaries. Gender, Work \& Organization, 5(4), 195-206.

Al-Amoudi, I., ve Willmott, H. (2011). Where constructionism and critical realism converge: Interrogating the domain of epistemological relativism. Organization Studies, 32(1), 27-46.

Aliefendioğlu, H. ve Özbilgin, M. F. (2001). Kadın, toplumsal cinsiyet ve cinsellik araştırmalarında araştırmacı ve katılımcı ilişkisi: Yeni arayışlar ve yönelimler. Kadin/Woman 2000, 2(2), 87-106.

Alvesson, M. ve Billing, Y. D. (2009). Understanding gender and organizations. Sage.

Alvesson, M., Hardy, C. ve Harley, B. (2008). Reflecting on reflexivity: Reflexive textual practices in organization and management theory. Journal of management studies, 45(3), 480-501. 
Ayaz, N. (1993). Türkiye'de Çalışan Kadınların Sorunlarına Yönelik Bir Inceleme: Tekstil Işkolundan Örneklerç. Dokuz Eylül Üniversitesi Iktisadi ve İdari Bilimler Fakültesi Dergisi, 8 (1), 175-191.

Calás, M. B. ve Smircich, L. (1999). From the 'woman's point of view': Feminist approaches to organization studies. Studying organization: Theory and method, 212-251.

Cunliffe, A. L. (2003). Reflexive inquiry in organizational research: Questions and possibilities. Human relations, 56(8), 983-1003.

Çitçi, O. (1979). Türk Kamu Yönetiminde Kadın Görevliler. N. Abadan-Unat,(Der.), Türk Toplumunda Kadın. Ankara: Türk Sosyal Bilimler Derneği, 241-270.

Dameron, S. ve Durand, T. (Eds.). (2017). The Future of Management Education: Volume 2: Differentiation Strategies for Business Schools. Springer.

Fernando, W. D. A., ve Cohen, L. (2014). Respectable femininity and career agency: Exploring paradoxical imperatives. Gender, work \& organization, 21(2), 149-164.

Fleetwood, S. (2005). Ontology in organization and management studies: A critical realist perspective. Organization, 12(2), 197-222.

Fletcher, A. J. (2017). Applying critical realism in qualitative research: methodology meets method. International Journal of Social Research Methodology, 20(2), 181-194.

Fletcher, J. K. (2004). The paradox of postheroic leadership: An essay on gender, power, and transformational change. The leadership quarterly, 15(5), 647-661.

Francis, B. (2002). Relativism, realism, and feminism: An analysis of some theoretical tensions in research on gender identity. Journal of gender studies, 11(1), 39-54.

Gergen, M. ve Jones, K. (2008). A conversation about performative social science. In Forum: Qualitative Social Research, 9(2), 1-12. Bournemouth University, Fern Barrow, Poole, Dorset, BH12 5BB, UK.

Gherardi, S. (2003). Feminist theory and organization theory: A dialogue on new bases. In The Oxford handbook of organization theory.

Grosser, K. ve Moon, J. (2019). CSR and feminist organization studies: Towards an integrated theorization for the analysis of gender issues. Journal of Business Ethics, 155(2), 321-342.

Gunnarsson, L., Martinez Dy, A. ve Van Ingen, M. (2016). Critical realism, gender and feminism: Exchanges, challenges, synergies.

Gutek, Barbara A. ve Cohen, A. (1987) Sex ratios, sex-role spillover, and sex at work. Human Relations, 40(2), $97-115$.

Hardy, C., Phillips, N. ve Clegg, S. (2001). Reflexivity in organization and management theory: A study of the production of the researchsubject. Human relations, 54(5), 531-560.

Harris, H. (1995). Organizational influences on women' $\mathrm{s}$ career opportunities in international management. Women in Management Review, 10(3), 26-31.

Heilman, M. E. (1983). Sex bias in work settings: The lack of fit model. Research in Organizational Behavior, 5, 269-298.

Heilman, M. E. (1995). Sex stereotypes and their effects in the workplace: What we know and what we don't know. Journal of Social Behavior and Personality, 10, 3-26

Holmes, J. ve Schnurr, S. (2006). 'Doing femininity'at work: More than just relational practice 1. Journal of Sociolinguistics, 10(1), 31-51.

Johnson, P. ve Duberley, J. (2003). Reflexivity in management research. Journal of management studies, 40(5), 1279-1303.

Johnson, P. ve Duberley, J. (2003). Reflexivity in management research. Journal of management studies, 40(5), 1279-1303.

Kutal, G. Sosyal Politika Açısından Çalışan Kadının Sorunları. Kiplas Dergisi, 12.

Koray, M. (1993). Çalışma Yaşamında Kadın Gerçekleri (23). Banka, Sigorta İşçileri Sendikası.

Lewis, P. (2014). Postfeminism, femininities and organization studies: Exploring a new agenda. Organization Studies, 35(12), 1845-1866. 
Lordoğlu, K. (1987). Yüksek Öğretim Gören Kadın İşgücü Adayları ve Çalışma Eğilimleri. ODTÜ Gelişme Dergisi, 14.

Maier, F., Meyer, M. ve Steinbereithner, M. (2016). Nonprofit organizations becoming business-like: A systematic review. Nonprofit and Voluntary Sector Quarterly, 45(1), 64-86.

Meyerson, D. E. ve Kolb, D. (2000). 'Moving out of the 'armchair': developing a framework to bridge the gap between feminist theory and practice'. Organization, 7, 553.

Nogueira, C., Saavedra, L. ve Neves, S. (2007). Critical (feminist) psychology in Portugal: Will it be possible?. Annual Review of Critical Psychology.

Noor, K. B. M. (2008). Case study: A strategic research methodology. American journal of applied sciences, 5(11), 1602-1604.

Oliver, M. (1997). Emancipatory research: realistic goal or impossible dream. Doing disability research, 2, 1531.

Ozbilgin, M. F. (2009). From journal rankings to making sense of the world. Academy of Management Learning \& Education, 8(1), 113-121.

Özbilgin, M. F. ve Erbil, C. (2019). Yönetim Çalışmaları Alanındaki Kısır Yöntem İkilemlerini Dışaçekimsel ve Geçmişsel Yaklaşım ve Eleştirel Gerçekçilikle Yöntem Yelpazesine Dönüştürmek (Transforming the Barren Dichotomies of Method in the Field of Management Studies into a Spectrum with Abductive and Retroductive Approaches and Critical Realism). Yönetim ve Çalı̧̧ma Dergisi, 3(1), 1-24.

Özen, Ş. (2000). Türk Yönetim/Organizasyon Yazininda Yöntem Sorunu: Kongre Bildirileri Üzerine Bir Inceleme. DAÜ Turizm Arastirmalari Dergisi, 1(1), 89-118.

Özen, Ş. (2000). Türk Yönetim/Organizasyon Yazininda Yöntem Sorunu: Kongre Bildirileri Üzerine Bir Inceleme. DAÜ Turizm Arastirmalari Dergisi, 1(1), 89-118.

Özen, Ş. (2002). Türkiye'deki Örgütler/Yönetim Araştirmalarinda Törensel Görgülcülük Sorunu. Yönetim Araştırmaları Dergisi, 2(Ekim).

Özen, Ş. (2002). Türkiye'deki Örgütler/Yönetim Araştirmalarinda Törensel Görgülcülük Sorunu. Yönetim Araştırmaları Dergisi, 2(Ekim).

Sayer, A. (2004). Why critical realism. Critical realist applications in organisation and management studies, 620.

Schein, E. H. (1996). Culture: The missing concept in organization studies. Administrative science quarterly, 229-240.

Shaw, S. J. (2010). What a woman ought to be and to do: Black professional women workers during the Jim Crow era. University of Chicago Press.

Sinclair, A. (1998), Doing Leadership Differently: Gender, Power and Sexuality in a Changing Business Culture, Melbourne University Press, Melbourne.

Sinclair, A. (2000). Teaching Managers about Masculinities: Are You Kidding? Management Learning, 31(1), $83-101$.

Smirthwaite, G. ve Swahnberg, K. (2016). Comparing critical realism and the situated knowledges approach in research on (in) equity in health care: An exploration of their implications. Journal of Critical Realism, 15(5), 476-493.

Tranfield, D., Denyer, D. ve Smart, P. (2003). Towards a methodology for developing evidence-informed management knowledge by means of systematic review. British Journal of Management, 14, 207-222.

Willmott, H. (2011). Journal list fetishism and the perversion of scholarship: reactivity and the ABS list. Organization, 18(4), 429-442.

Wilson, F. (1996). Research note: Organizational theory: Blind and deaf to gender?. Organization studies, 17(5), 825-842.

Yıldırım, A. ve Şimşek, H. (2011). Sosyal Bilimlerde Nitel Araştırma Yöntemleri. Ankara: Seçkin Kitabevi. 